Original Research Article

\title{
Experiential learning of ethnopharmacological sources of drugs through rotating trios micro discussion in MBBS students: an innovative I-tray teaching methodology
}

\author{
Mohammed Imran ${ }^{1}$, Chintan M. Doshi ${ }^{2}$, Darshan Kharadi², Saima Naaz ${ }^{3}$
}

\begin{abstract}
${ }^{1}$ Department of Pharmacology, KD Medical College Hospital and Research Center, Mathura, Uttar Pradesh, India

${ }^{2}$ Department of Pharmacology, Pacific Institute of Medical Sciences, Umarda, Udaipur, India

${ }^{3}$ Freelance artist, MFA Delhi, India
\end{abstract}

Received: 11 October 2019

Revised: 16 November 2019

Accepted: 18 November 2019

*Correspondence to:

Dr. Chintan M. Doshi,

Email: doshichintan2@

gmail.com

Copyright: (C) the author(s), publisher and licensee Medip Academy. This is an openaccess article distributed under the terms of the Creative Commons Attribution NonCommercial License, which permits unrestricted noncommercial use, distribution, and reproduction in any medium, provided the original work is properly cited.

\begin{abstract}
Background: Complementary and alternative medicine is very robust in some parts of the world. The study was done to impart the experiential learning related to sources of drugs in a pharmacy practical class for MBBS students.

Methods: We used ingredient-tray (I-Tray) teaching tool consisting of two parts to generate experiential learning in MBBS students about ethno pharmacological sources of drugs. Innovatively designed I -tray filled with two sizes plastic containers $(100 \mathrm{ml}$ and $50 \mathrm{ml}$ sizes used for collecting biological samples of sputum and urine) containing crude drug medicinal sources which were arranged in gutters of the tray. They were sorted into five categories such as plants (flowers of Vinca rosea, bark of Terminalia arjuna, roots of Rauwolfia serpentine and Eucalyptus leaves); animals (formalin preservatives freshwater leech, shells and vaccines); minerals (kaolin, potassium permanganate and charcoal); oils and others. Three charts of 4 square feet sizes were used for demonstration of synthetic, microbiological and genetically engineered drug sources.
\end{abstract}

Results: The students' approval rate of I-tray was mean yes value of 105.78 for a tool of active learning out of total 113 students. Around 100\%, 98.23\% and $97.35 \%$ students utilised application of concept (cognition), faculty of smell (affective) and volunteering (psychomotor) in the class. However female students had statistically significant score against this set up of the class depicting gender specificity of the learning process.

Conclusions: Thus teaching traditional sources of drugs through I-tray impart higher order social, place based and experiential learning of medicine.

Keywords: Ethno-pharmacological sources of drugs, Experiential learning, Pharmacy practical, MBBS students, Rotating trios

\section{INTRODUCTION}

The World Health Organisation reports around eighty percent use of complementary and alternative medicine (CAM) therapies in Asian countries and a first choice in some of the economical backward areas. ${ }^{1,2}$ Some of the published literature also supports the official CAM utilization from 9 to $65 \% .^{3,4}$ The practitioners from the modern system of medicine also prescribe up to $12 \%$ of Ayurvedic drugs to their patients. ${ }^{5}$ The ethno- pharmacological sources of drugs have taken the humanity out from difficult situations of drug resistance many a times. One such scenario is the discovery of the drugs for malaria where initially the Cinchona species and then Artemesia annua provided the solutions. ${ }^{6-8}$ There is widespread prescription of papaya leaf (Carica papaya) tablets in dengue haemorrhagic fever and milk thistle (Sylibum marianum) syrup for liver disorder by Allopathic prescribers in Indian subcontinent. But the teaching and curriculum design in MBBS courses could 
not find importance and proper way of andragogic delivery of the natural sources of drugs to the future prescribers of modern system of medicine (Figure 1). This may needs innovative teaching and hard work by the trainer.

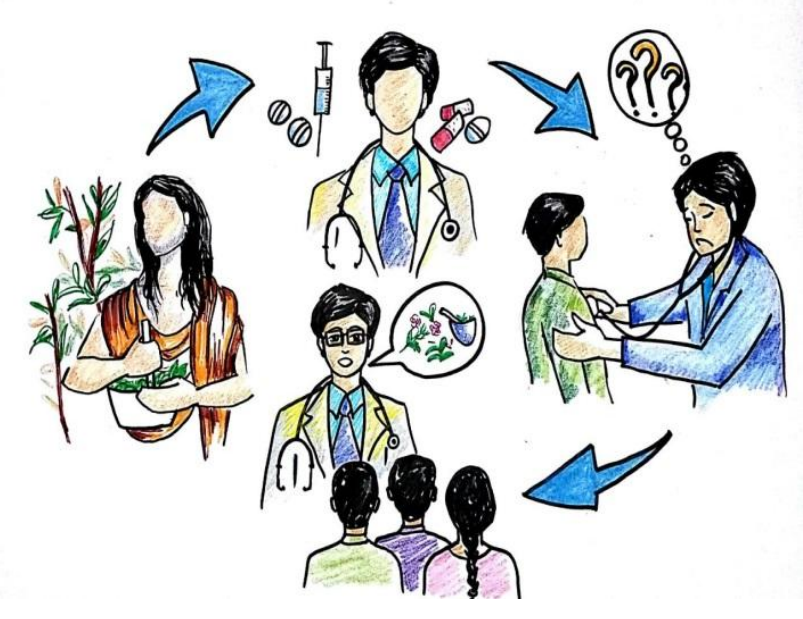

Figure 1: Teaching ethnopharmacology to students of modern medicine.

The skill of teaching is an art and science. ${ }^{9}$ It is undergoing paradigm shift in professional courses from didacticism to facilitative learning in a more collaborative way. ${ }^{10}$ Franklin in 1750 once said "tell me and I forget, teach me and I remember, involve me and I learn". 11 Therefore experiential learning (EL) is more powerful a teaching model than learning-by-doing or hands on learning because it includes experiencing (doing), reflection and applying. ${ }^{12}$ It involves application of carefully chosen experiences banked by reflection, critical analysis and synthesis. These experiences motivate students to initiate, decide and make them accountable for results.

The most important part of the EL process is the active engagement of the students in experimenting, investigating, problem solving, leading, creativity, constructing and being curious for more. They remain part of the class physically, soulfully, socially, emotionally and intellectually making the learning task authentic. It makes the changes in personality for laying foundations for the future learning and experiences. It broadens the students' relationship with the teacher, to other students, to the self and rest of the world and this approach connects the experiences with the real world events. ${ }^{13}$ Active learning and place based education are few examples of EL. ${ }^{14}$

Whatever may be the mode but the essential part of the active learning is the discussion and reflection to apply the taught concept in real life situations. Any technique which encourages the students to talk and participate in limited time classrooms settings is active learning technique. ${ }^{15}$ It necessitates the freedom to the students to discuss the ideas with slight freedom and flexibility with respect to the direction of class. Thus active learning promotes knowledge transfer among the students, active engagement in the peer group and developing problem solving skills. ${ }^{16}$

The EL thus makes the students motivated, contributed to the positive changes in their attitude and self-directed to learning. In addition to that teachers have the onus to discover different means and tools to impart the teaching innovatively and in student centric approach. The teacher can use novel strategies to help students develop skills of problem solving, articulation, theorize, interpretation and use higher learning domains through relay learning facilitation. ${ }^{17,18}$

The teacher's role as a facilitator encourages students to think in critical manners, make them accept the challenges for learning and develop an attitude to overcome them through transformational learning. However highest level of facilitation is achieved by critical andragogy by empowering the students in debating the cognition and developing affective and psychomotor learning approaches.

Although learning the content is important but learning process lies at the heart of the EL. ${ }^{19}$ It firstly includes the hands-on or minds-on experiences of the students; secondly they share the feelings of their experiences, their reactions and observations with their peers. This finally leads to the reflection for the future learning, discussion and analysis to connect it to real life examples and settings. Moreover innovations are required for teaching disconnected art of ethno-pharmacological sources to the modern medicine practitioners.

The consideration of cultural sensitivity are critical for fruitful interactions of the subjects for global engagement. ${ }^{20}$ The teaching of pharmacy in India to the medical, dental, physiotherapy and nursing students can only be imparted by the medical specialists who are postgraduate in medical pharmacology as per the Medical Council of India teacher eligibility qualifications guidelines. It also ascribes 2:1 time allotment to the practical and theory teaching respectively. The subject is allotted two hundred hours of practical and 100 hours of theory teaching in Indian medical colleges taught over a period of one and half years which will be reduced to one year in new curriculum of competency based medical education. ${ }^{21}$ The MBBS students are expected to develop hands-on ability, logical thinking, critical analysis, team work through such training and develop relevance with the community to become the competent Indian medical graduate. ${ }^{22}$ Therefore improvement of pharmacology and pharmacy practical teaching is of paramount importance to develop a comprehensive knowledge of the subject for future prescribers and for connecting the traditions to the modernity for finding the solution in difficult therapeutic situations. 
The traditional pharmacology teaching was didactic with animal experimental content and lesser focus on the pharmacy. As the animal experiments have been banned by many of the countries including India in undergraduate and postgraduate teachings, thus majority of the medical colleges in India are experiencing disconnect between the training content and the requirement of the future prescribers. ${ }^{23-25}$ The students get disengaged to learning in traditional didactic lecturing that is being used to impart the practical aspects of pharmacology rather a self-directed hands on experience learning.

We have used active learning and place based EL approaches in our study as an EL tool. The EL is defined as anything that captures the students thinking in doing things and thinking about those things which they are doing. It also provided the opportunities to read, write, talk and listen reflecting onto the students as they approach the course content through problem solving exercises, informal small groups, simulations, case studies, role-playing and other activities which require students to apply what they are learning. We incorporated the local medicinal plants parts such as flowers of Vinca rosea, bark of Terminalia arjuna, roots of Rauwolfia serpentina, Eucalyptus leaves and some of the readily available types of oils to explain the plant sources of drugs. We also included freshwater leech to explain the drug obtained from the saliva of this animal and dried shells from Asia's largest manmade freshwater Jaisamand Lake in Udaipur.

The present idea was implemented by creating an innovative tool (I-tray) to reform the practical pharmacology content. It was created to shift the passive learning to active EL for creating a niche for traditional natural sources of drugs. The students participated and studied actively remaining engaged to the class in a similar fashion as audience in a magic show where volunteers are called from the audience. The teacher used more flexible and diversified technique to generate initiative, enthusiasm and break the monotony. Thus the present I -tray methodology with EL and rotating trios has been evaluated for teaching potentially relevant pharmacology practical such as sources of drugs to the budding prescribers of modern system of medicine.

\section{METHODS}

The institutional ethical committee approval was taken for delivering the specific learning objective of ethnopharmacological sources. The sessions were taken in the department of Pharmacology, Pacific Institute of Medical Sciences, Udaipur from April 2017 to July 2019. An innovative tray called ingredient tray (I-tray) was prepared (Figure 2a) for the purpose of delivery of EL in MBBS students. It is made up of polyvinyl material with almost a square shape measuring $31.5 \times 28 \mathrm{cms}$ and a generalised depth of $5 \mathrm{cms}$ having five gutters in different directions and sizes with all around overhanging margins.
The partitioned area depicted as ' $\mathrm{i}$ ' is large gutter measuring $31.5 \times 9.5 \mathrm{cms}$. While the area 'ii' on Y-axis is a smaller gutter measuring $7.5 \times 6 \mathrm{cms}$. The three interconnecting gutters marked as 'iii' are $25.3 \times 5.3 \mathrm{Cms}$ each. This tray is generally available for keeping otorhinolaryngology instruments. However it can be customised as per the liberty of teaching faculty.

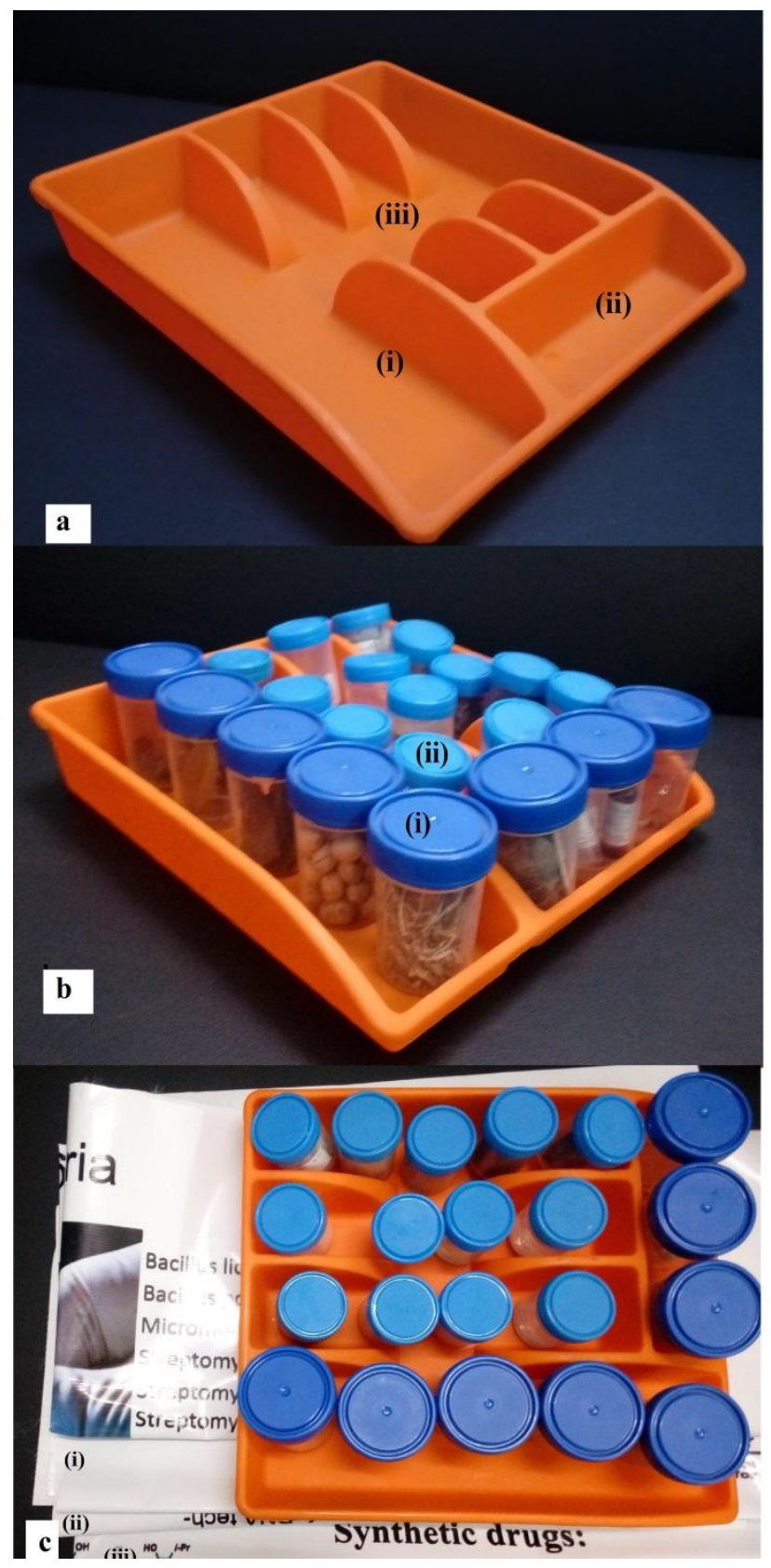

Figure 2 (a) (i): Large gutter measuring $31.5 \times 9.5 \mathrm{cms}$, (ii): smaller gutter measuring $7.5 \times 6 \mathrm{cms}$ and (iii): three interconnecting gutters measuring $25.3 \times 5.3 \mathrm{cms}$ each; (b) (i): Five containers on left with five plant sources and three on the right with animal sources,

(ii): minerals, oils and other sources of drugs such as gums, tannins and resins; (c) (i): Charts with microbiological sources, (ii): genetically engineered drugs, (iii): synthetic and semi-synthetic drugs. 
When put on a flat surface considering it a two dimensional square area (Figure 2b), one large gutter in $\mathrm{Y}$-axis was used for keeping five bigger containers (depicted as ' $i$ ') of plant sources including items such as roots of Rauwolfia serpentina (contains alkaloid to treat hypertension), Dhatura seeds (source for atropine), Arjuna bark (used for its antihypertensive action), Vinca rosea flowers (used for commercial production of anticancer drugs) and Eucalyptus leaves (oil is obtained). The second gutter was smaller in size on $\mathrm{X}$-axis perpendicular to the biggest gutter holding three containers for the items related to the animal sources such as Vials of various vaccines, leech (for explaining the drugs such as Hirudin, Lepirudin etc.,) and many dried shells of Shell fish (for explaining the glucosamine source). The smaller containers (depicted as 'ii') were kept in third area which was in between these two gutters. This area was divided into three interconnecting gutter. One gutter had five examples for mineral sources such as raw Iron ore (for iron), calcium carbonate rocks (for calcium), kaolin material (aluminium silicates), potassium permanganate and wood charcoal. The second gutter had one examples of oils from essential (camphor), fixed (coconut) and mineral (liquid paraffin) category each. The third gutter had one example from gums (Gum acacia), tannins (iodine tincture) and resins (oleoresin from the plasters). Two more small containers $(50 \mathrm{ml})$ each having normal water was kept in the tray for the activity of mixing the oil and water (to experience the immiscibility) on the dorsum of their hand. In addition to that the complete customisation of I-Tray for this practical included the three large charts (Figure 2c) each measuring $4 " \times 4$ " as well. First chart had examples of drugs from microbiological sources, the second chart had examples of drugs from genetically engineered sources and third chart included the synthetic and semi-synthetic drugs.

Thus three charts and one complete I-tray with small and large containers were used as a tool for EL of traditional sources of drugs. It was followed up by a questionnaire which was filled in by the students at the end of the class regarding the validation and evaluation of the I-tray tool for teaching sources of drugs practical and scoring for rotating trios by MBBS students.

We conducted a class similar to a show of a magician who holds the hat in the hands and takes out different items from it in a surprise and awe. Our hat in this case was a tray called 'I-tray'.

We set up the class of 55-60 students over two days in micro groups of foursome students facing each other for discussion like sitting around a restaurant table called 'rotating trios' instead of facing a preacher in a church arrangement. ${ }^{26}$ Various ethno pharmacological items of the tray were circulated time to time while the teacher explaining and relating everything contextually. We tried to involve students throughout the progression of the class by higher learning domains of cognition, affection and psychomotor through application of concepts by themselves, use of smell in learning differences and volunteering with the teacher. The volunteerism was similar to a magician who calls somebody from the audience to become the part of the set up.

The topic 'sources of drugs' were chosen for practical class of two hours for the active and place based education EL. The educator was moving in between the chairs intermittently and remained in front of everyone like taking orders from the restaurant table.

Before the delivery of the content in the class, each student was asked to pick up one slip randomly which was coded in such a way that the students who got slips having number one was called for volunteering. The students with slip bearing number two was asked to smell the oils and share the findings and experiences with the peers. And number three was asked to make a small patch of oil on the dorsum of the hand and subsequently he or she was asked to pour few drops of water onto the patch followed by few drops of liquid paraffin to show the immiscibility of two liquid phase to all students trailed by relevance of gum acacia as the emulsifying or suspending agent was told. The students with number four were asked the relevant questions and called in front of all the students to summarise the topic occasionally.

\section{RESULTS}

The students were asked about the effectiveness of the class at the end of the session. They were given questionnaires containing 14 questions [Table 1] related to their perception, interaction and higher learning order achieved through the class.

The responses of the students were recorded in four options for each question as yes, no, can't say and scored out of 10 with respect to the traditional teaching. The students approved the teaching methodology by ticking on Yes in aggregates of 14 questions with an average of 105.78 students out of total 113 students. An average of 2.85 said 'no' to some questions in the table. However, average value of category 'can't say' was little higher than the category 'no' with a value of 4.35 [Table 2].

The class with the I-tray was liked by all the students with enthusiasm and energy as indicated by the comparable average percentage responses of males and females of 94.03 and 92.85 respectively. However the score values recorded as magnitude of change from traditional teaching shows a higher numerical responses in the males than the females [Table 3].

This methodology provides the opportunity to explore higher learning domains for the students, reflection of the content as per the need of the students and customisation of classes based on the gender preferences. 
Table 1: Questions asked from the students to evaluate the effectiveness of the I-tray methodology.

\begin{tabular}{|ll|}
\hline S. No. & Questions asked with the stem "could this I-tray methodology \\
\hline $\mathbf{1}$ & Encourage me to be more curious? \\
\hline $\mathbf{2 .}$ & Encourage student participation? \\
\hline $\mathbf{3 .}$ & Encourage me to look for more information on the topic deal with? \\
\hline $\mathbf{4 .}$ & Encourage learning? \\
\hline $\mathbf{5 .}$ & More satisfactory teaching? \\
\hline $\mathbf{6 .}$ & Impart the learning requirement of pharmacology course? \\
\hline $\mathbf{7 .}$ & Strengthen students learning interest and ability in pharmacology knowledge acquired in the lecture? \\
\hline $\mathbf{8 .}$ & Increase the sharing and team work among the students? \\
\hline $\mathbf{9 .}$ & Improve students' interaction with the teachers and other students? \\
\hline $\mathbf{1 0}$. & Improve students' abilities to use theories to analyse and solve problems? \\
\hline $\mathbf{1 1}$ & \begin{tabular}{l} 
Observation of phenomenon, instruments and ingredients is superior to lecture class and viewing pictures \\
\hline $\mathbf{1 2}$.
\end{tabular}$\quad$ Ining computer? \\
\hline $\mathbf{1 3}$. & Use smell in learning the topic for making associations? \\
\hline $\mathbf{1 4}$. & Motivate students to volunteer in front of the peer group? \\
\hline
\end{tabular}

Table 2: Percentage responses of the students in four categories against each question.

\begin{tabular}{|lllll|}
$\begin{array}{l}\text { Questi- } \\
\text { on no. }\end{array}$ & Yes (\% mean) & No (\% mean) & Cant' say (\% mean) $) \begin{array}{l}\text { Magnitude of likeness out of } \mathbf{1 0} \text { with respect } \\
\text { to the traditional learning (\% mean) }\end{array}$ \\
\hline 1. & 98.23 & 0.00 & 1.77 & 88.10 \\
\hline 2. & 95.58 & 1.77 & 2.65 & 86.55 \\
\hline 3. & 92.04 & 4.42 & 3.54 & 85.29 \\
\hline 4. & 96.46 & 2.65 & 0.88 & 89.96 \\
\hline 5. & 85.84 & 8.85 & 5.31 & 86.95 \\
\hline 6. & 79.65 & 4.42 & 15.93 & 73.78 \\
\hline 7. & 92.92 & 0.88 & 6.19 & 84.25 \\
\hline $\mathbf{8 .}$ & 88.50 & 6.19 & 5.31 & 81.37 \\
\hline 9. & 96.46 & 0.88 & 2.65 & 88.76 \\
\hline $\mathbf{1 0}$ & 96.46 & 0.00 & 3.54 & 86.08 \\
\hline $\mathbf{1 1}$ & 92.92 & 3.54 & 3.54 & 85.69 \\
\hline 12. & 100.00 & 0.00 & 0.00 & 93.78 \\
\hline 13. & 98.23 & 0.88 & 0.88 & 91.11 \\
\hline $\mathbf{1 4}$ & 97.35 & 0.88 & 1.77 & 90.91 \\
\hline
\end{tabular}

Table 3: Mean values of magnitude of change or percentage likeness of the class over traditional teaching.

\begin{tabular}{|lllllllll|}
\hline S. No. & $\begin{array}{l}\text { Male } \\
\text { (Yes) }\end{array}$ & $\begin{array}{l}\text { Female } \\
\text { (Yes) }\end{array}$ & $\begin{array}{l}\text { Male } \\
\text { (No) }\end{array}$ & $\begin{array}{l}\text { Female } \\
\text { (No) }\end{array}$ & $\begin{array}{l}\text { Male } \\
\text { (Can't say) }\end{array}$ & $\begin{array}{l}\text { Female } \\
\text { (Can't say) }\end{array}$ & $\begin{array}{l}\text { Male } \\
\text { (Score) }\end{array}$ & Female (Score) \\
\hline Mean & 68.64 & 37.14 & 1.78 & 1.25 & 2.57 & 2.08 & 642.87 & 335.83 \\
\hline Mean of the \% & 94.03 & 92.85 & 2.44 & 2.67 & 3.52 & 4.46 & 88.07 & 83.96 \\
\hline
\end{tabular}

We found that the standard normal distribution (SND) and unpaired $t$ test values between the means of the male score and female score are statistically significant. The SND value is 3.73 corresponding to the $\mathrm{p}=0.001$ while unpaired t-test showed $\mathrm{p}$ value of 0.06 suggesting $94 \%$ confidence interval for the obtained scores.

\section{DISCUSSION}

The pharmacology is a very important subject in second professional year devoted to the para-clinical subjects in medical colleges in India. It is an important subject taught in nursing, pharmacy, veterinary and dentistry as well. ${ }^{27-}$ ${ }^{29}$ It acts as a bridging subject connecting basic medical sciences and clinical subjects along with the microbiology, pathology and forensic medicine. It is taught in the traditional manners where teacher delivers the didactic lectures. Even the practical classes have become redundant after the ban of animals use in undergraduate and postgraduate teaching by the Ministry of health and family welfare, government of India. ${ }^{30}$ The use of practical teaching hours have largely been utilised to extend the theoretical power point presentation of different concepts of pharmacology practical topics. 
We devised this innovative I-tray methodology on the basis of the notion that framing an activity makes it experiential rather the content itself. We chose the ethnopharmacological topic of 'sources of drugs' for active learning as it connects to the local needs of wide use of CAM. The CAM is being promoted by the government of India and substantial number of physicians routinely encounters the preparations of natural sources in their practice. In addition to that the understanding of the sources matches the learning objectives of the pharmacology course. It also complements the overall foundation of pharmacology.

We found very high approval rate of the I-tray teaching methodology as a concept of the 'magician with a hat' however the class pattern has got a very peculiar result from the students. The male approval score for this particular class arrangement was higher than the female score and unpaired t-test showed statistical significance with a $p$ value of 0.06 suggesting gender male specific likeness of this teaching learning methodology. Although majority of the female students like the innovative I-tray strategy along with the EL however there is statistically significant difference between the two genders of the class. The reason for the same may be that a particular gender resists non-lecturing approach more than the other needing a gender specific customisation of the class teaching methodology or more frequent classes of EL. ${ }^{31}$

\section{CONCLUSION}

The conventional pharmacology training for one and half years of MBBS course has been unable to meet the relevance of the actual community needs due to neglect of the pharmacy and its imparting teaching methodology. MBBS students enjoy class of traditional 'sources of drugs' being taught and found it to be culturally relevant in the curriculum of modern system of medicine. The 'Itray' reformed teaching not only enhanced students' interest but also provide importance of pharmacology practical teaching for developing their professional knowledge. It instils enthusiasm, encouragement, selfdirected learning, team work and problem solving skills.

Funding: No funding sources

Conflict of interest: None declared

Ethical approval: The study was approved by the Institutional Ethics Committee

\section{REFERENCES}

1. World Health Organisation. WHO Traditional Medicine Strategy 2014-2023. Geneva: WHO; 2014.

2. Bodeker G, Kronenberg F, Burford G. Policy and public health perspectives in traditional, complementary and alternative medicine. An overview. In: Bodeker G, Burford G, eds. Traditional, complementary and alternative medicine: Policy and Public Health Perspectives. London: Imperial College Press; 2007: 9-40.
3. Chen YF, Chang JS. Complementary and alternative medicine use among patients attending a hospital dermatology clinic in Taiwan. Int $\mathbf{J}$ Dermatol. 2003;42:616-21.

4. Imran M, Amir M, Naqvi H, Naaz S. The prevalence and pattern of usage of Ayurveda, Unani and home remedies in younger adults of rural North India. Int $\mathbf{J}$ Green Pharm. 2017;11(2):1-6.

5. Verma U, Sharma R, Gupta P, Gupta S, Kapoor B. Allopathic vs. Ayurvedic practices in tertiary care institutes of Urban North India. Indian J Pharmacol. 2007;39:52-4.

6. Buss AD, Waigh RD. Natural products as leads for new pharmaceuticals. In: Wolff ME, ed. Burger's Medicinal Chemistry and drug discovery: Principles and practice. Vol.1. New York. John Wiley and Sons, Inc; 1995: 983-1033.

7. Wongsrichanalai C, Pickerd AL, Wernsdorfer WH, Meshnick SR. Epidemiology of drug-resistant malaria. Lancet Infect Dis. 2002;2(4):209-18.

8. Cragg GM, Newman DJ. Natural products: a continuing source of novel drug leads. Biochim Biophys Acta. 2013;1830(6):3670-95.

9. Brownhill B. The Socratic Method. In: Jarvis P, ed. The theory and practice of Teaching. London: Kogan; 2002: 70-78.

10. Griffiths Y, Ursik K. Using active learning to shift the habits of teaching in health care education. Internet J Allied Health Sci Practice. 2004;2:1-5.

11. Psychology Today. Twenty awe-inspiring quotes for teachers and parents. The Moment of Youth. Available at: http://www.psychologytoday. com/blog/ the-moment-youth/201309/20-awe-inspiring-quotes teachers-and-parents. Accessed on 28 June 2019.

12. Wurdinger SD, Carlson JA. Teaching for experiential learning: Five approaches that work. Lanham Maryland: Rowman and Little field Education; 2010.

13. Yardley S, Pim W, Dornan T, Dornan T. Experiential learning: AMEE Guide No. 63, Medical Teacher, 2012;34(2):e102-15.

14. Wurdinger S, Rudolph J. Teaching practices that impose student learning: Five experiential approaches. J Teach Learn. 2009;6(1):1-13.

15. Bonwell CC, Eison JA. Active learning: Creating excitement in the classroom. ASHE-ERIC higher Education Report No. 1. The George Washington University. The school of education and Human development. Washington DC; 1991.

16. Machemer PL, Crawford P. Student perceptions of active learning in a large cross-disciplinary classroom. Active Learn Higher Educ. 2007;8(1): 930 .

17. Smedley BD, Stith AY, Nelson AR, ed. Unequal treatment. Confronting racial and ethnic disparities in healthcare. Institute of Medicine of the National Academics. Washington, DC; National Academies Press (US); 2003.

18. Hobson W, Mier AR, Cochella S, Hala SV, Alder SJSC, Croskell SE. Caring for underserved: using patient and physician focus groups to inform 
curriculum development. Ambulat Pediatric. 2005;5:90-5.

19. Dornan T, Boshuizen H, King N, Scherpbier A. Experience based learning: A model linking the processes and outcomes of medical students' workplace learning. Med Educ. 2007;41:84-91.

20. Kawaguchi-Suzuki M, Hogue MD, Khanfar NM, Lahoz MR, Law MG, Parekh J, et al. Cultural Sensitivity and Global Pharmacy Engagement in Asia: India, Indonesia, Malaysia, Philippines, and Vietnam. Am J Pharm Educ. 2019;83(4):7215.

21. Medical Council of India. Regulations on Graduate Medical Education, 1997. Available at: http://www. Mciindia.org/tools/announcement/Revised_GME_ 2012.pdf. Accessed June 28, 2019.

22. Medical council of India, 2017. Available at: http://www.mciindia.org/tools/announcement/MCI booklet. Accessed on 25 June 2019.

23. Medical council of India, New Delhi, amendment notification of 8 July 2009 to the minimal standard requirements for medical colleges with 150 admissions annually, regulations, 1999. Available at: http://www.mciindia.org/helpdesk/how_to_start/ST ANDARD\%20FOR\%20150.pdf. Accessed on 25 June 2019.

24. UGC. University Grant Commission, 2014. Available at: http://www.ugc.ac.in/pdfnews/6819407_ugcletter zoology.pdf. Accessed on 25 June 2019.

25. Satish GR, Laxminarayana K, Jayanthi CR. Reassessment of dispensing pharmacy and animal experiments in undergraduate practical pharmacology curriculum: feedback from students. Int J Basic Clin Pharmacol. 2016;5:285-92.

26. University of Waterloo. Centre for teaching excellence. Resources. Teaching tips. Learning activities. Rotating Trios. Available at: https://uwater loo.ca/centre-for-teaching-excellence/teaching-resour ces/teaching-tips/developing-assignments/groupwork/group-work-classroom-types-small-groups. Accessed on 17 July 2017.

27. Ahmed MW, Dass P, Gulabani M, Ahmed R, Javedar $\mathrm{P}$, Mishra R. Undergraduate MBBS and BDS students' opinion based survey on current teaching practices in pharmacology and changes recommended for betterment of the same. J Evol Med Dent Sci. 2014;3(70):14923-9.

28. Badyal DK. Pharmacology education in India: Challenges ahead. Indian J Pharmacol. 2016;48(1):S3-4.

29. Goyal RK, Bhise SB, Srinivasan BP, Rao CM, Sen T, Koneri R. Curriculum for pharmacology in pharmacy institutions in India: Opportunities and challenges. Indian J Pharmacol. 2014;46: 241-5.

30. Gonwar K. UGC Calls for total ban on animal dissection for academic purposes. Deccan Chronicle. 2014. Available at: http://www.deccanchronicle.com/ 140806/nation-current-affairs/article/ugc-calls-totalban-animal-dissection-academic-purposes. Accessed on 25 June 2019.

31. Sasikumar N. Impact of active learning strategies to enhance student performance. Innovare $\mathbf{J}$ Educ. 2014;2:1-3.

Cite this article as: Imran M, Doshi CM, Kharadi D, Naaz S. Experiential learning of ethnopharmacological sources of drugs through rotating trios micro discussion in MBBS students: an innovative I-tray teaching methodology. Int J Basic Clin Pharmacol 2019;8:2729-35. 